\title{
Liquid biopsy using the supernatant of a pleural effusion for EGFR genotyping in pulmonary adenocarcinoma patients: a comparison between cell-free DNA and extracellular vesicle-derived DNA
}

\author{
Jong Sik Lee ${ }^{1 \dagger}$, Jae Young Hur ${ }^{1,3+}$, In Ae Kim ${ }^{1}$, Hee Joung Kim, ${ }^{1,2}$, Chang Min Choi ${ }^{4,5}$, Jae Chol Lee ${ }^{4,5}$,
}

Wan Seop Kim ${ }^{3}$ and Kye Young Lee ${ }^{1,2^{*}}$ (D)

\begin{abstract}
Background: EGFR genotyping in pulmonary adenocarcinoma patients who develop pleural effusions is mostly performed using cytology or cell block slides with low sensitivity. Liquid biopsy using the supernatant of pleural effusions may be more effective because they contain many components released by cancer cells. Extracellular vesicles (EVs) are known to carry oncogenic double-stranded DNA that is considered a notable biomarker. Here, we investigate the efficiency of liquid biopsy using cell-free DNA (cfDNA) and extracellular vesicle-derived DNA (EV-derived DNA) from the supernatant of pleural effusions for EGFR genotyping in patients with pulmonary adenocarcinoma.
\end{abstract}

Methods: Fifty pleural effusion samples from patients with pulmonary adenocarcinoma were evaluated. The supernatant, after removing the cell pellet by centrifugation, was used for liquid biopsy, and EVs were isolated from the pleural effusion by ultracentrifugation. EV-derived DNA and cfDNA were extracted separately, and EGFR genotyping was performed by the PNA clamping method.

Results: Among 32 patients who were EGFR-tyrosine kinase inhibitor (TKI) naïve with a known tissue EGFR genotype, liquid biopsy using EV-derived DNA from the pleural effusion supernatant showed 100\% matching results with tissue EGFR genotyping in 19 EGFR mutant cases and detected three additional EGFR mutations in patients with wild-type (WT) tissue. Liquid biopsy using cfDNA from pleural effusion supernatants missed two cases of tissue-based EGFR mutations and found two additional EGFR mutation cases. In 18 patients who acquired resistance to EGFR-TKI, EGFR genotyping using EV-derived DNA from the pleural effusion supernatant detected the T790 M mutation in 13 of 18 (72. 2\%) patients, and this mutation was detected in 11 (61.1\%) patients using cfDNA. By contrast, only three patients were found to present the T790 M mutation when using cell block or cytology slides.

(Continued on next page)

\footnotetext{
* Correspondence: kyleemd@kuh.ac.kr

† Jong Sik Lee and Jae Young Hur contributed equally to this work.

'Department of Pulmonary, Lung Cancer Center, Konkuk University Medical

Center and Medicine, Konkuk University School of Medicine, 120-1

Hwayang-dong, Gwangjin-Gu, Seoul 05030, Republic of Korea

${ }^{2}$ Department of Pulmonary Medicine, Konkuk University School of Medicine,

Seoul, Republic of Korea

Full list of author information is available at the end of the article
}

(c) The Author(s). 2018 Open Access This article is distributed under the terms of the Creative Commons Attribution 4.0 International License (http://creativecommons.org/licenses/by/4.0/), which permits unrestricted use, distribution, and

reproduction in any medium, provided you give appropriate credit to the original author(s) and the source, provide a link to the Creative Commons license, and indicate if changes were made. The Creative Commons Public Domain Dedication waiver (http://creativecommons.org/publicdomain/zero/1.0/) applies to the data made available in this article, unless otherwise stated. 
(Continued from previous page)

Conclusions: Liquid biopsy using the supernatant of pleural effusions showed significantly improved results for EGFR genotyping compared to those using conventional cell block or cytology samples. Liquid biopsy using EV-derived DNA is promising for EGFR genotyping, including T790 M detection in pulmonary adenocarcinoma patients who develop pleural effusions.

Keywords: Pleural effusion, Pulmonary adenocarcinoma, EGFR mutation, Extracellular vesicles, Liquid biopsy

\section{Background}

Malignant pleural effusion is shown in $11-32 \%$ of patients with advanced non-small cell lung cancer (NSCLC) [1, 2]. The diagnostic rates of pleural effusion for malignancy have a mean sensitivity of approximately 60\% (range 40-87\%) [3]. Pleural effusion for adenocarcinoma gives higher diagnostic rates than those for squamous cell or small cell carcinomas. EGFR genotyping using malignant pleural effusion is useful when adequate tissue is not available due to co-morbidities or other reasons. In those cases, cell pellet specimens, including cell block or cytology, are conventionally used. EGFR mutation detection using malignant pleural effusion is less invasive and shows equivalent mutation detection rates when compared with a tissue biopsy [4]. Recently, supernatant samples known to be highly effective for EGFR genotyping have shown concordance with tissue typing [4, 5]. cfDNA is frequently used for liquid biopsy due to its convenience but has intrinsic problems of DNA stability and a short half-life $(2 \mathrm{~h})[6,7]$.

Extracellular vesicles (EVs) are nanoparticles that contain bioactive molecules such as proteins and nucleic acids and have great potential as cancer biomarkers because the biomarkers are protected by a dual lipid membranous coat $[8,9]$. EVs are released in large quantities in various biological fluids, such as pleural effusions, plasma, urine, saliva and bronchoalveolar lavage fluid [10]. Recently, it has been demonstrated in various cancer cell lines that the majority of DNA associated with tumor exosomes is double-stranded, which highlights the translational value of exosomal DNA for its potential usefulness as a circulating biomarker for cancer detection $[9,11,12]$. Furthermore, we demonstrated that EV-derived DNA is much more highly efficient for EGFR genotyping than cfDNA in lung cancer patients [13]. On this basis, we investigated the feasibility of EGFR genotyping using the supernatant of pleural effusions in comparison with tissue-based genotyping in patients with pulmonary adenocarcinoma. We also compared the translational value of the cfDNA and EV-derived DNA extracted from the supernatant of pleural effusions for EGFR genotyping in EGFR-TKI-naïve patients and for detecting the T790 M mutation in patients with acquired resistance to EGFR-TKIs.

\section{Methods \\ Study population and pleural effusion samples}

Among patients diagnosed and treated for pulmonary adenocarcinoma with pleural effusion at Konkuk University Medical Center and Asan Medical Center between January 1, 2011 and December 31, 2015, fifty patients with archival pleural effusion samples were included in the analysis. Demographics and clinical data of the included patients were reviewed. This study was conducted in accordance with the amended Declaration of Helsinki. The study protocol was approved by the institutional review board of Konkuk University Medical Center and Asan Medical Center, and written informed consent was obtained from all patients. After $50 \mathrm{~mL}$ of a pleural effusion sample was centrifuged using Falcon $^{\mathrm{Tm}} 50 \mathrm{~mL}$ conical centrifuge tubes at $1000 \mathrm{~g}$ for $10 \mathrm{~min}$ at $4{ }^{\circ} \mathrm{C}$ to remove cells and debris, the supernatant of the pleural effusion was separated and stored at $-80^{\circ} \mathrm{C}$ until further evaluation.

\section{Extracellular vesicles (EVs) isolation and characterization}

Supernatant samples of the pleural effusions were each transferred to an ultracentrifuge tube and spun at 200,000 $\mathrm{g}$ for $1 \mathrm{~h}$ at $4{ }^{\circ} \mathrm{C}$. The volume of sample used for the isolation of EVs was $500 \mu \mathrm{L}$ of pleural effusion supernatant. The supernatant was carefully removed, and the pellet was resuspended in $200 \mu \mathrm{L}$ of PBS for DNA extraction. We eluted EV-derived DNA with $50 \mu \mathrm{L}$ of distilled water. The purified EV size was analyzed using NanoSight.

\section{Extraction of EV-derived DNA and cfDNA}

To eliminate free-floating DNA that exists outside of EVs, purified EVs were added to a microtube. Then, the EVs were treated with $10 x$ reaction buffer $(200 \mathrm{mM}$ Tris- $\mathrm{HCl}, \mathrm{pH} 8.3,20 \mathrm{mM} \mathrm{MgCl} 2$ ) and DNase I (Sigma, St. Louis, MO) and then incubated for $15 \mathrm{~min}$ at room temperature. To bind calcium and magnesium ions and to inactivate the DNase I, the sample was treated with stop solution (50 mM EDTA), and the microtube was heated at $70{ }^{\circ} \mathrm{C}$ for $10 \mathrm{~min}$ to denature the DNase I and then chilled on ice. After elimination of free-floating DNA, the EVs were lysed by mixing cell lysis buffer and detergent, and the EV-derived DNA was purified using the High Pure PCR Template Preparation Kit (Roche Diagnostics, Mannheim, Germany). The volume of sample used for the isolation of cfDNA was $500 \mu \mathrm{L}$ of 
pleural effusion supernatant. cfDNA was isolated from the supernatant of the pleural effusion using the High Pure PCR Template Preparation Kit (Roche Diagnostics, Mannheim, Germany). We eluted cfDNA with $50 \mu \mathrm{L}$ of distilled water. The purification of DNA was measured using a NanoDrop Spectrophotometer (Thermo Fisher Scientific, Waltham, MA USA). The concentration and distribution of double-strand DNA was measured using a 4200 TapeStation (Agilent Technologies, Santa Clara, CA, USA).

\section{EGFR genotyping}

The EGFR genotyping was tested using the PNAClamp $^{\text {in }}$ EGFR Mutation Detection Kit (Panagene, Daejeon, Korea) with the peptide nucleic acid (PNA)-mediated PCR clamping method. Each sample was tested in eight individual reaction tubes for 29 EGFR DNA mutations. All reactions had a total reaction volume of $20 \mu \mathrm{L}$, which contained $70 \mathrm{ng}$ of template DNA, a primer, a PNA probe set, and a fluorescence dye PCR master mix. All reagents were included with the kit. PNA-mediated clamping PCR reactions were performed using a CFX96TM (Bio-Rad, Hercules, CA). The PCR cycling conditions were as follows: 5 min at $94{ }^{\circ} \mathrm{C}$ followed by 40 cycles at $94{ }^{\circ} \mathrm{C}$ for $30 \mathrm{~s}$, $70{ }^{\circ} \mathrm{C}$ for $20 \mathrm{~s}, 63^{\circ} \mathrm{C}$ for $30 \mathrm{~s}$, and $72{ }^{\circ} \mathrm{C}$ for $30 \mathrm{~s}$. The efficiency of PCR clamping was determined by measuring the threshold cycle $(\mathrm{Ct})$ value. $\mathrm{Ct}$ values for the control and mutation assays were obtained from the fluorescence amplification plots. The delta $\mathrm{Ct}(\Delta \mathrm{Ct})$ value was as follows: $\Delta \mathrm{Ct}-1=$ [standard $\mathrm{Ct}-$ sample $\mathrm{Ct}$ ]. The cut-off $\Delta \mathrm{Ct}-1$ was defined as 2.0 for the 29 mutations in EGFR DNA [14].

\section{Statistical analysis}

Data were summarized as medians with interquartile range (IQR) with non-normal distribution. We used the Wilcoxon signed rank test to test the significance of differences in DNA concentration of EV-derived and cfDNA. The EGFR genotype agreement between the tissue and EV-derived or cfDNA was measured by Cohen's kappa coefficient. All statistical analyses were carried out using SPSS Statistics version 24 (IBM Corp, Chicago, IL, USA), and a $P$ value $<0.05$ was regarded as statistically significant.

\section{Results}

\section{Characteristics of patients}

We analyzed 50 pleural effusion samples that were obtained from patients with pulmonary adenocarcinoma. The median age of all patients was 67.5 years (IQR 59.8-73.3), and 25 (50\%) were female. Twenty-five (50\%) patients were non-smokers; 14 (28\%) were ex-smokers, and 11 (22\%) were current smokers. EGFR genotyping based on tumor tissue showed 19 deletions in $22(44 \%)$ patients, L858R in $15(30 \%)$, and wild-type EGFR in 13 (26\%). Of the 50 patients, 32 were EGFR-TKI naïve and presented pleural effusion at the time of diagnosis or after treatment failure. Eighteen patients displayed acquired resistance to EGFR-TKI, who developed pleural effusion after TKI treatment (Table 1).

\section{Characterization of isolated EVs from the supernatant of pleural effusions}

The size and concentration of EVs isolated from malignant pleural effusion and parapneumonic effusion were analyzed. Isolated EVs from the supernatant of the pleural effusion of an EGFR-TKI naïve patient (case 5) showed a mean size of $267.6 \mathrm{~nm}$ and concentration of $4.18 \times 10^{8}$ particles $/ \mathrm{mL}$, but isolated EVs from the supernatant of parapneumonic effusion of a patient with bacterial pneumonia displayed a mean size of $174.3 \mathrm{~nm}$ and concentration of $1.10 \times 10^{9}$ particles/ $\mathrm{mL}$. When comparing between malignant pleural effusion and parapneumonic effusion, the concentration of EVs isolated from parapneumonic effusion was higher than that from malignant effusion, and by contrast, the mean size of EVs isolated from malignant pleural effusion was larger than the mean size of those from isolated from parapneumonic effusion. Malignant pleural effusion exhibited bimodal EV distributions (Additional file 1: Figure S1A, B) [15, 16].

\section{Quantitative and qualitative characterization of EV-} derived DNA and cfDNA isolated from the supernatant of pleural effusions

EV-derived DNA and cfDNA were extracted from the supernatant of pleural effusions from patients who were EGFR-TKI naïve (case 9). TapeStation analysis showed that the concentration of EV-derived DNA from the supernatant of the pleural effusion was $3.18 \mathrm{ng} / \mu \mathrm{L}$, which was higher than the concentration of cfDNA $(2.31 \mathrm{ng} / \mu \mathrm{L})$. When comparing the distributions of double-stranded DNA (dsDNA) size between EV-derived DNA and cfDNA from the supernatant of a pleural effusion across all DNA size scales, EV-derived DNA from the supernatant of the pleural effusion showed higher intensity. cfDNA had a higher fraction of $600 \mathrm{bp}$ DNA fragments, displaying a noticeable peak around that size, as EV-derived DNA did not show this peak. When compared with cfDNA, EV-derived DNA contained more diverse-sized dsDNA fragments (Additional file 1: Figure S1C). Such difference between cfDNA and EV-derived DNA seems to arise when cfDNA is extracted from pleural effusions due to various matters such as small size of EV and lipoproteins that prevent lysis of EV lipid membrane, which leads to rare EV-derived DNA in the extracts. That is why EV is isolated from pleural effusions before DNA is extracted. 
Table 1 Clinical characteristics of the patients

\begin{tabular}{|c|c|c|c|}
\hline Patient classification & $\begin{array}{l}\text { All patients } \\
(N=50)\end{array}$ & $\begin{array}{l}\text { EGFR-TKI naïve } \\
\text { patients ( } N=32)\end{array}$ & $\begin{array}{l}\text { EGFR-TKI acquired-resistance } \\
\text { patients }(N=18)\end{array}$ \\
\hline Age, year, median (IQR) & $67.5(59.8-73.3)$ & $68.5(58.3-73.8)$ & $67.5(62.7-73.5)$ \\
\hline Sex, female & $25(50.0 \%)$ & $14(43.8 \%)$ & $11(61.1 \%)$ \\
\hline \multicolumn{4}{|l|}{ Smoking status } \\
\hline Non-smoker & $25(50.0 \%)$ & $13(40.6 \%)$ & $12(66.7 \%)$ \\
\hline Ex-smoker & $14(28.0 \%)$ & $9(28.1 \%)$ & $5(27.8 \%)$ \\
\hline Current smoker & $11(22.0 \%)$ & $10(31.3 \%)$ & $1(5.6 \%)$ \\
\hline \multicolumn{4}{|l|}{ Tumor EGFR mutation } \\
\hline Exon 19 deletion & $22(44.0 \%)$ & $10(31.3 \%)$ & $12(66.7 \%)$ \\
\hline L858R & 15 (30.0\%) & 9 (28.1\%) & $6(33.3 \%)$ \\
\hline Wild-type & $13(26.0 \%)$ & $13(40.6 \%)$ & 0 \\
\hline \multicolumn{4}{|l|}{ Histology } \\
\hline Adenocarcinoma & 50 & 32 & 18 \\
\hline
\end{tabular}

EGFR-TKI epidermal growth factor receptor tyrosine kinase inhibitor; IQR interquartile range

Agreement of EGFR genotyping using EV-derived DNA and cfDNA extracted from the supernatant of pleural effusions in EGFR-TKI naïve patients

Out of 32 patients who were EGFR-TKI naïve, tissue EGFR genotyping results revealed 19 EGFR mutant cases (10 in Exon 19del and 9 L858R) and 13 wild-type cases. EGFR genotyping using EV-derived DNA from the supernatant of the pleural effusions showed perfect agreement (19/19) with tissue EGFR genotyping across the 19 EGFR mutant cases, and this method identified three additional EGFR mutations (cases 20, 21 and 22) in cases in which tissue EGFR genotyping showed wild-type results. The percent agreement between EV-derived DNA and tissue genotyping was 91\% ( $\mathrm{K}=$ $0.861 ; p=0.000$ ) (Fig. 1, Additional file 2: Table S1). Since two patients (cases 20 and 22) did not undergo follow-up after lung cancer diagnosis, and one patient (case 21) died during EGFR-TKI treatment, tumor response to EGFR-TKI in the three additional EGFR mutant cases could not be verified. Compared with tissue EGFR genotyping for EGFR mutant cases, EGFR genotyping using cfDNA from the supernatant of pleural effusion detected 17 of the 19 (89\%) mutant cases. Although two patients (cases 10 and 19) were missing among the 19 mutant cases, two additional mutant cases (cases 20 and 21) were found among wild-type EGFR tissue cases. In EGFR genotyping using cfDNA, $88 \%$ of cases were concordant with tissue EGFR genotyping ( $\mathrm{K}$ $=0.810 ; p=0.000$ ) (Fig. 1, Additional file 2: Table S1).

T790 M detection using EV-derived DNA and cfDNA from the supernatant of pleural effusions in patients with acquired resistance to EGFR-TKI

T790 M detection was examined in 18 patients who manifested with pleural effusion after TKI treatment. Among the 18 patients, tissue EGFR genotyping showed Exon 19del in 12 patients and L858R in 6 patients. EGFR genotyping using EV-derived DNA from the supernatant

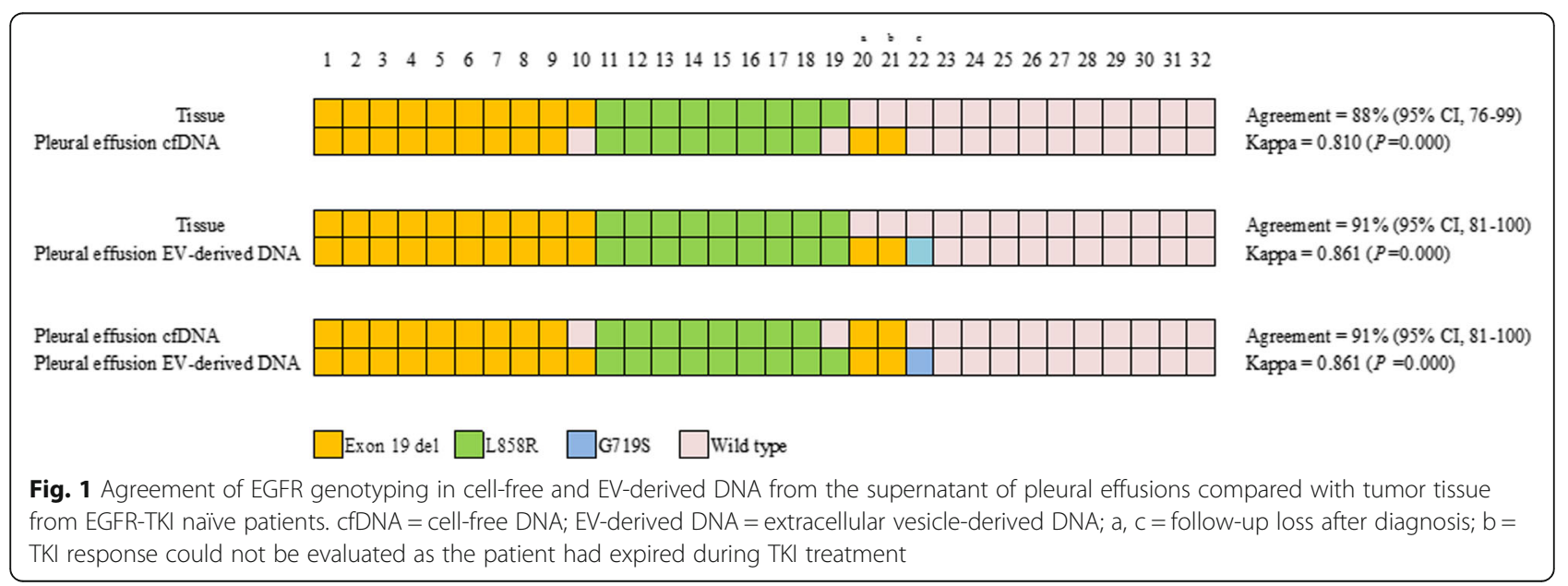


of the pleural effusions detected T790 M in 13 of the 18 (72\%) patients (nine patients with T790 M + Exon 19 del and four patients with T790 M + L858R). EGFR genotyping using cfDNA from the supernatant of the pleural effusions found T790 M in 11 of 18 (61\%) patients (seven patients with $\mathrm{T} 790 \mathrm{M}+$ Exon 19del and four patients with T790 M+L858R). When using EV-derived DNA from the supernatant of the pleural effusions for EGFR genotyping, two more T790 M mutations were detected in comparison with using cfDNA from the supernatant of the pleural effusions. By the conventional cell block or cytology slides which were made from the stored pleural effusion samples, because of not available tissue rebiopsy, only three patients were identified as T790 M positive (two patients with $\mathrm{T} 790 \mathrm{M}+$ Exon 19 del and one patient with $\mathrm{T} 790 \mathrm{M}+\mathrm{L} 858 \mathrm{R})$. We identified five out of nine patients who showed no tumor results from cell block or cytology samples that have the T790 M mutation when tested with EV-derived DNA (Fig. 2a, Additional file 3: Table S2). Furthermore, EGFR genotyping using EV-derived DNA from the supernatant of pleural effusions showed 100\% agreement with tissue EGFR genotyping $(\kappa=1.0 ; p=0.000)$. When using cfDNA from the supernatant of pleural effusions for EGFR genotyping, 17 out of 18 patients displayed agreement with the tissue EGFR genotyping, whereas one patient did not exhibit agreement ( $94 \%$ agreement, $\mathrm{K}=0.885 ; p=0.000$ ). When using a cell block or cytology, 39\% of the results were concordant with tissue EGFR genotyping $(\kappa=$ 0.214; $p=0.013$ ) (Fig. 2b, Additional file 3: Table S2).

\section{Comparison of the DNA concentration of EV-derived DNA and cfDNA from the supernatant of pleural effusions}

From 32 patients who were EGFR-TKI naïve and 18 who acquired EGFR-TKI resistance, the concentrations of EV-derived DNA and cfDNA from the supernatant of pleural effusions were measured by NanoDrop spectrophotometry. Overall, the DNA concentration of EV-derived DNA was higher than that of cfDNA (Additional file 2: Table S1, Additional file 3: Table S2). The median concentrations of EV-derived DNA and cfDNA were 22.7 (15.736.2) vs 14.7 (10.5-24.3) for patients who were EGFR-TKI naïve $(p=0.000)$ and $18.2(14.5-32.1)$ vs $15.4(11.1-21.8)$ for patients with acquired resistant to EGFR-TKI $(p=$
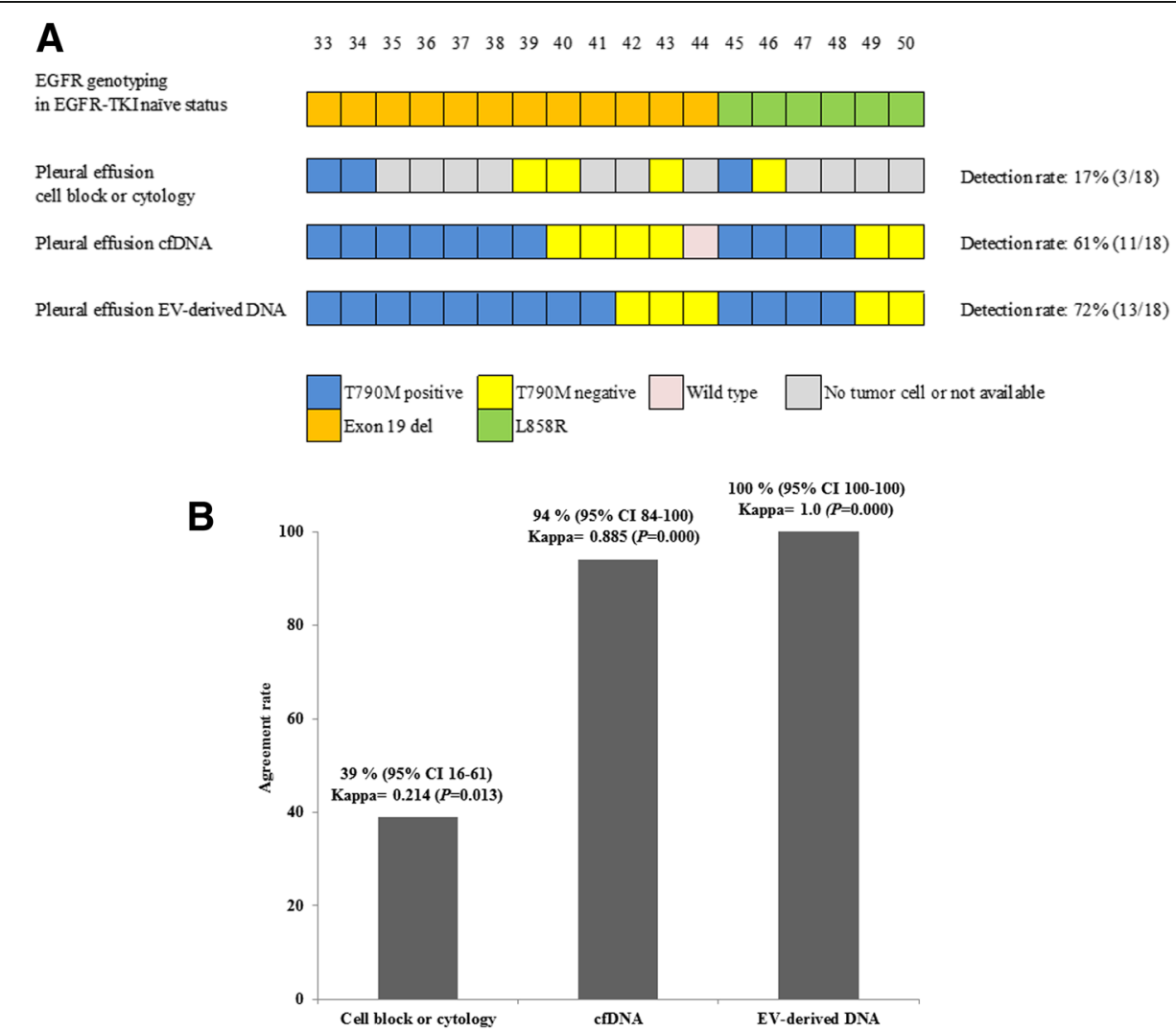

Fig. 2 Comparison of the EGFR genotyping between cell block or cytology, cell-free DNA and EV-derived DNA from the supernatant of pleural effusions in EGFR-TKI acquired-resistance patients. a Detection of the T790 M mutation using cell block or cytology, cfDNA and EV-derived DNA of pleural effusions. The detection rate of the T790 M mutation is 17,61,72\% in cell block or cytology, cfDNA, and EV-derived DNA of pleural effusions, respectively. $\mathbf{b}$ EGFR genotyping in accordance with tissue using a cell block or cytology, cfDNA and EV-derived DNA of pleural effusion are 39, 94, and 100\%, respectively. cfDNA = cell-free DNA; EV-derived DNA = extracellular vesicle-derived DNA 
0.001). The DNA concentration of EV-derived DNA from the supernatant of pleural effusions was significantly higher than that of cfDNA (Table 2).

\section{Discussion}

In general, tumor tissue obtained by surgery or biopsy has been used for EGFR genotyping in patients with NSCLC, among whom $27-31 \%$ of biopsies may fail to acquire tumor tissue that is suitable for EGFR genotyping at diagnosis or during disease progression [17]. When tumor tissue is not accessible, plasma cfDNA provides a promising diagnostic approach for detecting EGFR mutations and has been shown to be effective for diagnosis in meta-analysis [18, 19]. Previous studies into the detection of EGFR mutations using plasma cfDNA have noted low sensitivity compared with tumor tissue biopsies with an average sensitivity of $65-70 \%$ and high specificity (> 88\%) [20, 21]. For detecting T790 M among patients with NSCLC with acquired resistance, when repeated biopsy, circulating tumor cell (CTC) DNA, and circulating tumor DNA (ctDNA) were combined, T790 M was detected in 73\% of patients [22]. The combination of CTC and ctDNA genotyping allowed for the identification of the T790 M mutation in 14 (35\%) patients for whom the concurrent biopsy was either indeterminate or T790 M negative [22].

Recent studies have shown that the cell-free supernatant of pleural effusion might be a better resource for mutation detection than cell pellets [4], and EGFR mutations have been identified in supernatant samples [5]. In our study, EGFR genotyping using EV-derived DNA and cfDNA from the supernatant of pleural effusions in patients who were either EGFR-TKI naïve or who acquired resistance to EGFR-TKI showed good agreement with tissue EGFR genotyping ( $\kappa=0.861,0.810,1.0,0.885$ ). Furthermore, the detection rate of T790 M using EV-derived DNA from the supernatant of pleural effusions is more efficient than those using cell blocks or cfDNA.

Cancer cell-derived EVs might manifest the content of their cells of origin and maintain the potential to transfer specific oncogenic components to recipient cells [23]. Furthermore, several studies have also identified double-stranded DNA fragments in the EVs ranging from $100 \mathrm{~b}$ to $17 \mathrm{~kb}$ in size $[11,12]$. In the supernatants of pancreatic cancer cells and serum from patients with pancreatic cancer, Sanger sequencing analyses of polymerase chain reaction (PCR) amplicons have identified KRAS and TP53 mutations [11]. Since EVs are stable sources of genetic and protein cargos from the cell of origin, EVs are interesting as cancer biomarkers. The extensively fragmented nature of circulating cfDNA makes it difficult for this format to become generalizable in the context of genomic characterization through current next-generation sequencing (NGS) platforms [24]. By contrast, EV-derived DNA is long-stranded, has a high concentration, and would be easy to amplify, which means it could therefore be a candidate for NGS approaches. Previous studies have displayed a sensitivity of approximately $70 \%$ for EGFR genotyping by digital PCR [25], and our study demonstrated high sensitivity using a commonly available PNA clamping method.

In this study of pulmonary adenocarcinoma patients with pleural effusions that developed before or after EGFR-TKI treatment, we identified several interesting findings. First, in patients who were EGFR-TKI naïve, EGFR genotyping using EV-derived DNA from the supernatant of pleural effusions is in $100 \%$ agreement with tissue EGFR genotyping and has higher sensitivity, as this method was capable of detecting three additional mutant cases in patients who were otherwise diagnosed as tissue wild-type. We observed that EGFR genotyping using cfDNA from the supernatant of pleural effusions missed two tissue-proven EGFR mutations but detected two more mutant cases in patients diagnosed as tissue wild-type. Second, for detecting T790 M in patients with acquired resistance to EGFR-TKI with pleural effusion, using the supernatant of the pleural effusion to acquire EV-derived and cfDNA was significantly superior to the conventional use of cell pellet methodologies, such as cytology or using cell block specimens. Third, EV-derived DNA from the supernatant of pleural effusions outperformed cfDNA from pleural effusions for the EGFR genotyping of patients with pulmonary adenocarcinoma with pleural effusion.

Tumor necrosis in malignant pleural effusions produces a spectrum of DNA fragments with variable strand lengths due to random and incomplete genomic DNA digestion by deoxyribonucleases, most of which are long DNA fragments. It has been suggested that tumor cells may actively secrete DNA fragments, as has been observed for lymphocytes, extracellular vesicles of NSCLC and cancer cell lines [26-28]. The supernatant of pleural effusions might have high-quality DNA that could be amplifiable in the form of EV-derived DNA and cfDNA.

Table 2 Concentrations of cfDNA and EV-derived DNA from the supernatant of the pleural effusions

\begin{tabular}{lccll}
\hline & & \multicolumn{3}{c}{ Supernatant of pleural effusion } \\
\cline { 3 - 5 } & & cfDNA concentration $(\mathrm{ng} / \mu \mathrm{L})$ & EV-derived DNA concentration $(\mathrm{ng} / \mu \mathrm{L})$ & $P$ value \\
\hline EGFR-TKI naïve patients & $N=32$ & $14.7(10.5-24.3)$ & $22.7(15.7-36.2)$ & 0.000 \\
EGFR-TKI acquired resistance patients & $N=18$ & $15.4(11.1-21.8)$ & $18.2(14.5-32.1)$ & 0.001 \\
\hline
\end{tabular}

Data are expressed as median (IQR), cfDNA cell-free DNA, EV-derived DNA extracellular vesicle-derived DNA 
This study has several limitations. First, the number of patients included in the analysis was small, and only archival pleural effusions were examined. To confirm our observations, a large-scale study enrolling patients from multiple hospitals is needed. Second, this study was performed retrospectively, and the time points of pleural effusion analysis were not strictly controlled. Additionally, crucial data, such as the cell block or cytology of the pleural effusions, were missing for some patients. Third, third-generation EGFR-TKIs were not available in Korea until a few years ago. Therefore, tumor response to third-generation EGFR-TKIs was not evaluated. Further studies will be required to correlate the clinical response with EV-derived DNA and cfDNA genotyping from the supernatant of pleural effusions.

\section{Conclusions}

In conclusion, the supernatant of pleural effusions is particularly more effective for EGFR genotyping than conventional cytology or cell block samples for patients with pulmonary adenocarcinoma. EV-derived DNA from the supernatant of pleural effusions is promising for EGFR genotyping including T790 M detection in pulmonary adenocarcinoma patients who develop pleural effusion.

\section{Additional files}

Additional file 1: Figure S1. (A, B) EV quantification using NanoSight (Nanoparticle tracking analysis). EVs from the supernatant of malignant pleural effusions and parapneumonic effusions show mean sizes of 267.6 of $174.3 \mathrm{~nm}$ and concentrations $4.18 \times 10^{8}$ and $1.10 \times 10^{9}$ particles $/ \mathrm{ml}$, respectively. (C) EVs derived from the supernatant of malignant pleural effusions show a higher double-strand DNA concentration compared to that of cfDNA, as assessed by a microfluidic platform based on an electrophoretic system (4200 TapeStation, Agilent). (TIF 64 kb)

Additional file 2: Table S1. Comparison of the EGFR genotyping between tumor tissue, cell-free DNA and EV-derived DNA from the supernatant of pleural effusions in EGFR-TKI naive patients. (DOCX $19 \mathrm{~kb}$ )

Additional file 3: Table S2. DNA concentration of cell-free DNA and EV-derived DNA from the supernatant of pleural effusions in EGFR-TKI acquired-resistance patients. (DOCX $21 \mathrm{~kb}$ )

\section{Abbreviations}

cf: Cell-free; EGFR: Epidermal growth factor receptor; EV: Extracellular vesicle; IQR: Interquartile range; NGS: Next-generation sequencing; NSCLC: Non-small cell lung cancer; PCR: Polymerase chain reaction; PNA: Peptide nucleic acid; TKI: Tyrosine kinase inhibitor; WT: Wild-type

\section{Acknowledgements}

The authors thank Ja-Yeon Kim for her input on statistical analysis.

\section{Funding}

There was no funding for this study.

\section{Availability of data and materials}

The datasets used and/or analyzed during the current study are available from the corresponding author upon reasonable request.

\section{Authors' contributions}

JSL and JYH contributed to the data acquisition, data interpretation, and writing of the manuscript. IAK, HJK, CMC, JCL and WSK contributed substantially to the study design, data analysis and interpretation, and the writing of the manuscript. KYL is the guarantor of the entire manuscript and is responsible for the content of the manuscript, including the data collection and analysis. All authors read and approved the final manuscript.

\section{Ethics approval and consent to participate}

The study protocol was approved by the Institutional Review Board of Konkuk University Medical Center and Asan Medical Center and was conducted in accordance with the amended Declaration of Helsinki. All participants provided written informed consent before enrollment.

\section{Consent for publication}

Not applicable

\section{Competing interests}

The authors declare that they have no competing interests.

\section{Publisher's Note}

Springer Nature remains neutral with regard to jurisdictional claims in published maps and institutional affiliations.

\section{Author details}

'Department of Pulmonary, Lung Cancer Center, Konkuk University Medical Center and Medicine, Konkuk University School of Medicine, 120-1 Hwayang-dong, Gwangjin-Gu, Seoul 05030, Republic of Korea. ${ }^{2}$ Department of Pulmonary Medicine, Konkuk University School of Medicine, Seoul, Republic of Korea. ${ }^{3}$ Department of Pathology, Konkuk University School of Medicine, Seoul, Republic of Korea. ${ }^{4}$ Department of Pulmonary and Critical Care Medicine, University of Ulsan, College of Medicine, Asan Medical Center, Seoul, Republic of Korea. ${ }^{5}$ Department of Oncology, University of Ulsan, College of Medicine, Asan Medical Center, Seoul, Republic of Korea.

Received: 8 January 2018 Accepted: 27 November 2018

Published online: 10 December 2018

\section{References}

1. Morgensztern D, Waqar S, Subramanian J, Trinkaus K, Govindan R. Prognostic impact of malignant pleural effusion at presentation in patients with metastatic non-small-cell lung cancer. J Thorac Oncol. 2012;7(10):1485-9.

2. William WN Jr, Lin HY, Lee JJ, Lippman SM, Roth JA, Kim ES. Revisiting stage IIIB and IV non-small cell lung cancer: analysis of the surveillance, epidemiology, and end results data. Chest. 2009;136(3):701-9.

3. Hooper $C$, Lee YC, Maskell N: Investigation of a unilateral pleural effusion in adults: British Thoracic Society pleural disease guideline 2010. Thorax 2010, 65 Suppl 2:ii4-17.

4. Lin J, Gu Y, Du R, Deng M, Lu Y, Ding Y. Detection of EGFR mutation in supernatant, cell pellets of pleural effusion and tumor tissues from nonsmall cell lung cancer patients by high resolution melting analysis and sequencing. Int J Clin Exp Pathol. 2014;7(12):8813-22.

5. Shin S, Kim J, Kim Y, Cho SM, Lee KA. Assessment of real-time PCR method for detection of EGFR mutation using both supernatant and cell pellet of malignant pleural effusion samples from non-small-cell lung cancer patients. Clin Chem Lab Med. 2017;55(12):1962-9.

6. Dawson SJ, Tsui DW, Murtaza M, Biggs H, Rueda OM, Chin SF, Dunning MJ, Gale D, Forshew T, Mahler-Araujo B, et al. Analysis of circulating tumor DNA to monitor metastatic breast cancer. N Engl J Med. 2013;368(13):1199-209.

7. El Messaoudi S, Rolet F, Mouliere F, Thierry AR. Circulating cell free DNA: Preanalytical considerations. Clin Chim Acta. 2013;424:222-30.

8. Yanez-Mo M, Siljander PR, Andreu Z, Zavec AB, Borras FE, Buzas El, Buzas K, Casal E, Cappello F, Carvalho J, et al. Biological properties of extracellular vesicles and their physiological functions. J Extracell Vesicles. 2015;4:27066.

9. Thakur BK, Zhang H, Becker A, Matei I, Huang Y, Costa-Silva B, Zheng Y, Hoshino A, Brazier H, Xiang J, et al. Double-stranded DNA in exosomes: a novel biomarker in cancer detection. Cell Res. 2014;24(6):766-9.

10. Vanni L, Alama A, Grossi F, Dal Bello MG, Coco S. Exosomes: a new horizon in lung cancer. Drug Discov Today. 2017;22(6):927-36. 
11. Kahlert C, Melo SA, Protopopov A, Tang J, Seth S, Koch M, Zhang J, Weitz J, Chin $L$, Futreal A, et al. Identification of double-stranded genomic DNA spanning all chromosomes with mutated KRAS and p53 DNA in the serum exosomes of patients with pancreatic cancer. J Biol Chem. 2014;289(7):3869-75.

12. Lee TH, Chennakrishnaiah S, Audemard E, Montermini L, Meehan B, Rak J. Oncogenic ras-driven cancer cell vesiculation leads to emission of doublestranded DNA capable of interacting with target cells. Biochem Biophys Res Commun. 2014;451(2):295-301.

13. Hur JY, Kim HJ, Lee JS, Choi CM, Lee JC, Jung MK, Pack CG, Lee KY. Extracellular vesicle-derived DNA for performing EGFR genotyping of NSCLC patients. Mol Cancer. 2018;17(1):15.

14. Kim HJ, Lee KY, Kim YC, Kim KS, Lee SY, Jang TW, Lee MK, Shin KC, Lee GH, Lee JC, et al. Detection and comparison of peptide nucleic acid-mediated real-time polymerase chain reaction clamping and direct gene sequencing for epidermal growth factor receptor mutations in patients with non-small cell lung cancer. Lung cancer. 2012;75(3):321-5.

15. Santana SM, Antonyak MA, Cerione RA, Kirby BJ. Cancerous epithelial cell lines shed extracellular vesicles with a bimodal size distribution that is sensitive to glutamine inhibition. Phys Biol. 2014;11(6):065001.

16. Shender VO, Pavlyukov MS, Ziganshin RH, Arapidi GP, Kovalchuk SI, Anikanov NA, Altukhov IA, Alexeev DG, Butenko IO, Shavarda AL, et al. Proteome-metabolome profiling of ovarian cancer ascites reveals novel components involved in intercellular communication. Mol Cell Proteomics. 2014;13(12):3558-71.

17. NLCA annual report 2015. National Lung Cancer Audit, Royal college of Physicians. 2015. https://www.rcplondon.ac.uk/projects/outputs/nlca-annualreport-2015. Accessed 11 Dec 2017.

18. Qiu M, Wang J, Xu Y, Ding X, Li M, Jiang F, Xu L, Yin R. Circulating tumor DNA is effective for the detection of EGFR mutation in non-small cell lung cancer: a meta-analysis. Cancer Epidemiol Biomarkers Prev. 2015;24(1):20612.

19. Luo J, Shen L, Zheng D. Diagnostic value of circulating free DNA for the detection of EGFR mutation status in NSCLC: a systematic review and metaanalysis. Sci Rep. 2014;4:6269

20. Li Z, Zhang Y, Bao W, Jiang C. Insufficiency of peripheral blood as a substitute tissue for detecting EGFR mutations in lung cancer: a metaanalysis. Target Oncol. 2014;9(4):381-8.

21. Douillard JY, Ostoros G, Cobo M, Ciuleanu T, Cole R, McWalter G, Walker J, Dearden S, Webster A, Milenkova T, et al. Gefitinib treatment in EGFR mutated caucasian NSCLC: circulating-free tumor DNA as a surrogate for determination of EGFR status. J Thorac Oncol. 2014;9(9):1345-53.

22. Sundaresan TK, Sequist LV, Heymach JV, Riely GJ, Janne PA, Koch WH, Sullivan JP, Fox DB, Maher R, Muzikansky A, et al. Detection of T790M, the acquired resistance EGFR mutation, by tumor biopsy versus noninvasive blood-based analyses. Clin Cancer Res. 2016;22(5):1103-10.

23. Choi D, Lee TH, Spinelli C, Chennakrishnaiah S, D'Asti E, Rak J. Extracellular vesicle communication pathways as regulatory targets of oncogenic transformation. Semin Cell Dev Biol. 2017:67:11-22.

24. Mouliere F, Robert B, Arnau Peyrotte E, Del Rio M, Ychou M, Molina F, Gongora C, Thierry AR. High fragmentation characterizes tumour-derived circulating DNA. PLoS One. 2011;6(9):e23418.

25. Bernabe $\mathrm{R}$, Hickson N, Wallace A, Blackhall FH. What do we need to make circulating tumour DNA (ctDNA) a routine diagnostic test in lung cancer? Eur J Cancer. 2017;81:66-73.

26. Schwarzenbach H, Nishida N, Calin GA, Pantel K. Clinical relevance of circulating cell-free microRNAs in cancer. Nat Rev Clin Oncol. 2014;11(3):145-56.

27. Thery C, Ostrowski M, Segura E. Membrane vesicles as conveyors of immune responses. Nat Rev Immunol. 2009;9(8):581-93.

28. Bronkhorst AJ, Wentzel JF, Aucamp J, van Dyk E, du Plessis L, Pretorius PJ: Characterization of the cell-free DNA released by cultured cancer cells. Biochim Biophys Acta 2016, 1863(1):157-165.

Ready to submit your research? Choose BMC and benefit from:

- fast, convenient online submission

- thorough peer review by experienced researchers in your field

- rapid publication on acceptance

- support for research data, including large and complex data types

- gold Open Access which fosters wider collaboration and increased citations

- maximum visibility for your research: over $100 \mathrm{M}$ website views per year

At $\mathrm{BMC}$, research is always in progress.

Learn more biomedcentral.com/submissions 